\title{
PENINGKATAN PENGETAHUAN ORANGTUA MENGENAI DAMPAK PENGGUNAAN GADGET PADA ANAK USIA DINI DI TKK TUNAS HARAPAN BOGOR
}

\author{
Arlends Chris ${ }^{1}$, Sari Mariyati Dewi ${ }^{2}$ dan Novendy ${ }^{3}$ \\ ${ }^{1}$ Bagian Histologi, Fakultas Kedokteran Universitas Tarumanagara Jakarta \\ Email: arlendsc@fk.untar.ac.id \\ ${ }^{2}$ Bagian Histologi, Fakultas Kedokteran Universitas Tarumanagara Jakarta \\ Email: sarid@fk.untar.ac.id \\ ${ }^{3}$ Bagian Ilmu Kesehatan Masyarakat, Fakultas Kedokteran Universitas Tarumanagara Jakarta \\ Email: nnovendy@gmail.com
}

\begin{abstract}
The development of advances in computer technology is overgrowing. In today's modern life, humans cannot live without using this technology. The use of gadgets is increasing every year along with the development of information and communication technology. Users of this technology consist of all ages, including children. The use of gadgets in early childhood can have an impact on children's physical and mental health. The impact on physical health is impaired growth and development in children, including cognitive disorders. The impact on mental health is from social-emotional disorders to psychological disorders in children. For this reason, it is necessary to take preventive measures against the effects that arise on children. The way is to increase parental knowledge through counseling about the impact of using gadgets in early childhood on health, especially children's eye health at TKK Tunas Harapan Bogor. A team carried out this Community Service (PKM) activity from the Faculty of Medicine and the Faculty of Psychology, Tarumanagara University, collaborating with the TKK Tunas Harapan School, Bogor. In addition to conducting outreach activities, pretest and post-test were also conducted for participants to assess knowledge on topics related to PKM. The activity results showed that there was an increase in knowledge of $50 \%$ of the participants after the counseling. This is expected to be useful for parents to anticipate and prevent various disorders in children due to excessive use of gadgets. In the future, it is hoped that there will be counseling and measurement of children's activities related to the use of gadgets, eye examinations for children, and tips for parents in limiting the use of gadgets, especially for early childhood.
\end{abstract}

Keywords: child development, gadget use, early childhood

\begin{abstract}
ABSTRAK
Perkembangan kemajuan teknologi komputer semakin berkembang dengan pesat. Pada kehidupan modern saat ini, manusia tidak mungkin hidup tanpa menggunakan teknologi tersebut. Penggunaan gadget semakin meningkat setiap tahunnya seiring dengan perkembangan teknologi informasi dan komunikasi. Penguna teknologi ini terdiri dari semua kalangan umur termasuk anak-anak. Penggunaan gadget pada anak usia dini dapat berdampak pada kesehatan fisik dan mental anak. Dampak kesehatan fisik berupa gangguan tumbuh kembang pada anak termasuk ganguan kognitif, sedangkan dampak pada kesehatan mental berupa gangguan sosial emosional hingga gangguan psikologis pada anak. Untuk itu perlu dilakukan tindakan pencegahan terhadap dampak yang timbul pada anak-anak. Salah satu caranya adalah dengan meningkatkan pengetahuan orangtua melalui penyuluhan tentang meningkatkan pengetahuan orangtua mengenai dampak penggunaan gadget pada anak usia dini terhadap kesehatan terutama kesehatan mata anak di TKK Tunas Harapan Bogor. Kegiatan Pengabdian Kepada Masyarakat (PKM) ini dilaksanakan oleh tim dari Fakultas Kedokteran dan Fakultas Psikologi Universitas Tarumanagara bekerjasama dengan Sekolah TKK Tunas Harapan Bogor. Selain dilaksanakan kegiatan penyuluhan, juga dilakukan pre-test dan post-test bagi peserta untuk menilai pengetahuan mengenai topik terkait PKM. Hasil kegiatan menunjukkan terdapat peningkatan pengetahuan sebanyak $50 \%$ dari peserta setelah dilakukan penyuluhan. Hal ini diharapkan dapat bermanfaat bagi orangtua guna mengantisipasi dan mencegah berbagai gangguan pada anak-anak akibat penggunaan gadget yang berlebihan. Untuk kedepannya diharapkan dapat dilakukan penyuluhan dan pengukuran aktifitas anak terkait penggunaan gadget, pemeriksaan mata anak dan tips bagi orangtua dalam melakukan pembatasan penggunaan gadget terutama bagi anak usia dini.
\end{abstract}

Kata Kunci: perkembangan anak, penggunaan gadget, anak usia dini

\section{PENDAHULUAN}

Gadget merupakan istilah perangkat perkembangan teknologi komunikasi berupa alat elektronik kecil yang memiliki banyak fungsi. Berbeda dengan alat elektronik lainnya, gadget selalu mengalami perkembangan secara teknologi sehingga memberikan kemudahan atau kepraktisan 
untuk penggunanya (Rosiyanti \& Muthmainnah, 2018). Sekarang ini penggunaan gadget, seperti ponsel pintar atau tablet, sudah menjadi kebutuhan sehari-hari. Setiap saat dan disetiap kesempatan orang selalu membuka ponsel pintar atau tablet yang selalu dibawanya. Statista Research Departemen (2015) menyatakan telah terjadinya peningkatan penggunaan gadget di seluruh dunia setiap tahunnya. Di Indonesia juga terjadi peningkatan penggunaan gadget setiap tahunnya dari $32,6 \%$ pada tahun 2014 menjadi 43,2\% pada tahun 2017, dengan mayoritas (91\%) menggunakan ponsel pintar (Indonesia Digital Landscape, 2018; Datareportal, 2018). Seperti pedang bermata dua, penggunaan gadget juga memiliki sisi positif dan negatif. Untuk proses pembelajaran dan pencarian berbagai informasi, gadget sangatlah bermanfaat. Anak-anak akan lebih mudah memahami pelajaran dengan melihat video pembelajaran yang terdapat pada aplikasi gadget. Bahkan informasi apapun yang diinginkan lebih mudah didapatkan dari gadget yang terhubungan dengan internet. Disisi lain penggunaan gadget dengan jangka waktu yang berlebihan dapat memberikan dampak buruk bagi pertumbuhan dan perkembangan anak, baik psikologi maupun fisik (Winther, 2017). Posisi duduk yang tidak baik saat menggunakan gadget dapat menimbulkan keluhan pada bahu dan pinggang (Straker et al., 2008). Gambar atau animasi yang dilihat pada gadget seringkali sangat menarik untuk anak sehingga membuat mata terpaku pada gambargambar yang terdapat pada gadget. Hal ini dapat menurunkan refleks kedipan pada mata anak sehingga mata anak menjadi mudah iritasi. Selain itu terdapatnya blue light pada monitor gadget dapat merusak sel saraf pada mata anak sehingga anak dapat mengalami age related macular degeneration (ARMD) (Aprilia, 2018). Memandang ponsel pintar pada satu jarak mata dalam jangka waktu lama akan menyebabkan otot mata kaku sehingga akomodasi mata terganggu (Kozeis, 2009). Selain kesehatan mata secara psikologis, penggunaan gadget yang tidak terkontrol dapat berdampak pada perkembangan psikologis anak. Kesejahteraan mental, hubungan sosial dan aktivitas fisik adalah bagian dari dampak penggunaan gadget pada anak usia dini (Winther, 2017).

Konsekuensi dari terlalu banyak melihat layar gadget dan menjadi malas bergerak, memiliki dampak berupa: anak-anak akan cenderung tidak memiliki keterampilan motorik halus yang diperlukan ketika memasuki usia sekolah, penguasaan kosa kata, keterampilan komunikasi dan kontak mata berkurang, keterlambatan perkembangan anak yang berhubungan dengan peningkatan penggunaan gadget, perhatian, pengambilan keputusan dan kontrol kognitif berkurang, juga berimbas pada kreatifitas. Selain itu juga ditemukan penurunan korteks otak secara prematur dari hasil pemindaian otak (American Optometric Association (AOA), 2019).

Hasil dari survai American Eye-Q 2018 American Optometric Association menyatakan bahwa orang tua khawatir terhadap penggunaan perangkat elektronik yang berkepanjangan akan merusak mata anak-anak mereka. Hasil survai juga menyebutkan 4 dari 5 orang tua melaporkan bahwa anak-anak mereka menghabiskan setidaknya satu jam sehari menggunakan komputer atau gadget (AOA, 2019). Banyak orangtua yang memberikan anaknya menggunakan gadget, ditambah dengan kurangnya pengetahuan orangtua mengenai dampak gadget terhadap perkembangan psikologis dan kesehatan khususnya kesehatan mata. Hal ini menyebabkan banyaknya anak-anak yang beresiko mengalami gangguan kesehatan dan perkembangan psikologis di kemudian harinya. Resiko ini juga dapat terjadi pada siswa di TKK Tunas Harapan Bogor, karena banyak orangtua yang mengijinkan anaknya yang masih berusia di bawah lima tahun (balita) menggunakan gadget seperti ponsel pintar atau tablet. Menyadari hal tersebut pimpinan TKK Tunas Harapan mengajukan permohonan kerjasama dengan FK UNTAR untuk mengadakan penyuluhan berupa dampak penggunaan gadget pada anak usia dini.

Mitra PKM yaitu TKK Tunas Harapan Bogor dengan alamat di Jalan Pahlawan No. 140-142, RT. 01/ RW. 08, Empang, Kecamatan Bogor Selatan, Kota Bogor, Jawa Barat. Jarak mitra dengan 
Universitas Tarumanagara adalah 63 kilometer. Sekolah TKK Tunas Harapan berpredikat akreditas A dan juga merupakan anggota dari Association of Christian Schools International (ACSI). Sekolah memiliki visi berupa terwujudnya mimpi dari para siswa, orang tua dan seluruh yang terlibat dalam kegiatan belajar mengajar serta damai sejahtera memenuhi mereka. Misi sekolah berupa para siswa memiliki disiplin rohani, mengetahui bakatnya dan mengetahui kekuatannya sehingga mereka memiliki visi serta mampu mengemukakannya dengan jelas secara aktratif. Nilai dari sekolah TKK Tunas Harapan Bogor adalah berani untuk berubah, bisa diandalkan, antusias, menarik, dan luar biasa (Sekolah Kristen Tunas Harapan, 2014; Tim Dapodik, n.d.; Pusat Data dan Teknologi Informasi Kementerian Pendidikan \& Kebudayaan, n.d.). Berdasarkan hasil diskusi dengan kepala sekolah, resiko dan dampak penggunaan gadget pada anak-anak dapat dimodifikasi dan dihindari. Kondisi ini dapat dicegah dengan memberikan pengetahuan kepada orangtua yang memiliki anak-anak agar dapat memperhatikan dan memberikan arahan kepada anak-anaknya mengenai durasi penggunaan gadget.

\section{METODE PELAKSANAAN PKM}

Berdasarkan permasalahan yang diuraikan pada latar belakang, kegiatan PKM ini terbagi menjadi beberapa tahapan yaitu: (a) Tahap pertama berupa koordinasi tim PKM dengan pihak sekolah TK Tunas Harapan Bogor untuk mengetahui masalah yang terjadi dan juga diskusi solusi yang akan diterapkan; (b) Tahap kedua berupa kesepakatan kerjasama dan kesediaan menjadi mitra PKM, yang disepakati dengan Memorandum of Agreement nomor 05/SKTH_TK/VII/2019 dan Nomor 019-KD/FK.Untar/VII/2019 antara Fakultas Kedokteran Universitas Tarumanagara dengan TKK Tunas Harapan Bogor; (c) Tahap ketiga pihak mitra mendata jumlah orangtua siswa sebagai calon peserta kegiatan PKM; (d) Tahap keempat pelaksanaan kegiatan PKM.

Pada tahap pelaksanaan, kegiatan PKM dilaksanakan pada tanggal 13 Juli 2019, dengan peserta adalah orangtua TKK Tunas Harapan Bogor. Pada kegiatan ini, dilakukan pre-test dan post-test bagi peserta PKM untuk menilai pengetahuan mengenai dampak penggunaan gadget terhadap kesehatan mata anak dan psikologisnya. Selanjutnya, hasil tes dilakukan analisis untuk mengukur perbedaan rerata pengetahuan sebelum dan sesudah penyuluhan.

Tim pelaksana kegiatan PKM ini melibatkan peran serta dosen sebagai narasumber dan mahasiswa yang membantu pelaksanaan kegiatan di sekolah seperti yang dapat dilihat pada Gambar 1 s.d Gambar 3. Dua orang dosen yang hadir sebagai narasumber, yaitu dokter yang memaparkan materi mengenai materi computer vision syndrome dan dampaknya terhadap kesehatan fisik dan mata anak, serta seorang psikolog yang menjelaskan dampak penggunaan gadget terhadap perkembangan psikologi anak. Gambar 4 menunjukan foto bersama antara kepala sekolah dan guru-guru TKK Tunas Harapan Bogor beserta tim PKM Universitas Tarumanagara.

\section{HASIL DAN PEMBAHASAN}

Kegiatan PKM dihadiri sebanyak 49 orangtua TKK Tunas Harapan Bogor (Gambar 5 dan Gambar 6). Kegiatan ini dikoordinasikan dan diatur oleh dr. Sari Mariyati Dewi, M.Biomed. Acara diawali dengan sambutan dari Ketua Tim PKM Dr. dr. Arlends Chris, M.Si, kemudian dilanjutkan sambutan dari pihak sekolah yang langsung disampaikan oleh Kepala Sekolah TKK Tunas Harapan. Kemudian acara dilanjutkan dengan penyuluhan dari kedua narasumber yaitu dr. Novendy, MKK., FISCM, FISPH dan Meiske Yunithree Suparman, M.Psi., Psikolog.

Total sebanyak 49 peserta yang ikut dalam kegiatan ini. Sebanyak 46 peserta yang mengisi pertanyaan pre-test dan 39 peserta yang mengisi pertanyaan post-test. Namun secara keseluruhan hanya 30 peserta yang mengerjakan pre-test dan post-test. Dari 30 peserta yang lengkap mengerjakan pre-test dan post-test didapatkan bahwa nilai median pre-test adalah 50 dan nilai median post-test adalah 66,67 Sebanyak 18 (60\%) peserta hasil pre-test dibawah nilai median, dan 
setelah dilakukan post-test didapatkan sebanyak 22 (73,3\%) peserta hasil post-test diatas nilai median. Peserta dikatakan mengalami peningkatan pengetahuan jika terjadi perbedaan nilai median post-test dan pre-test sebesar 16,67 poin. Jadi sebanyak $15(50 \%)$ peserta meningkat pengetahuannya (Tabel 1).

\section{Gambar 1}

Pembicara dengan Peserta

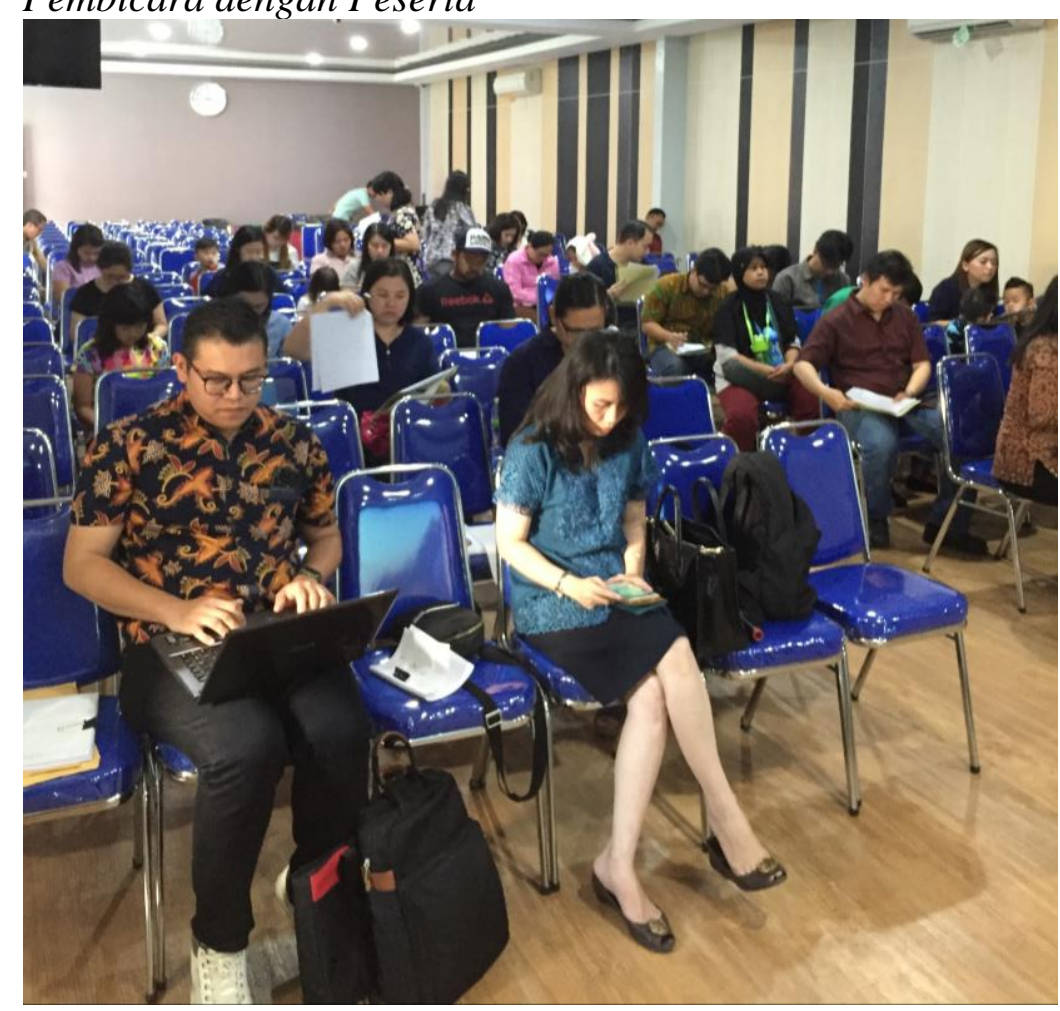

\section{Gambar 2}

Pembicara dr. Novendy, MKK

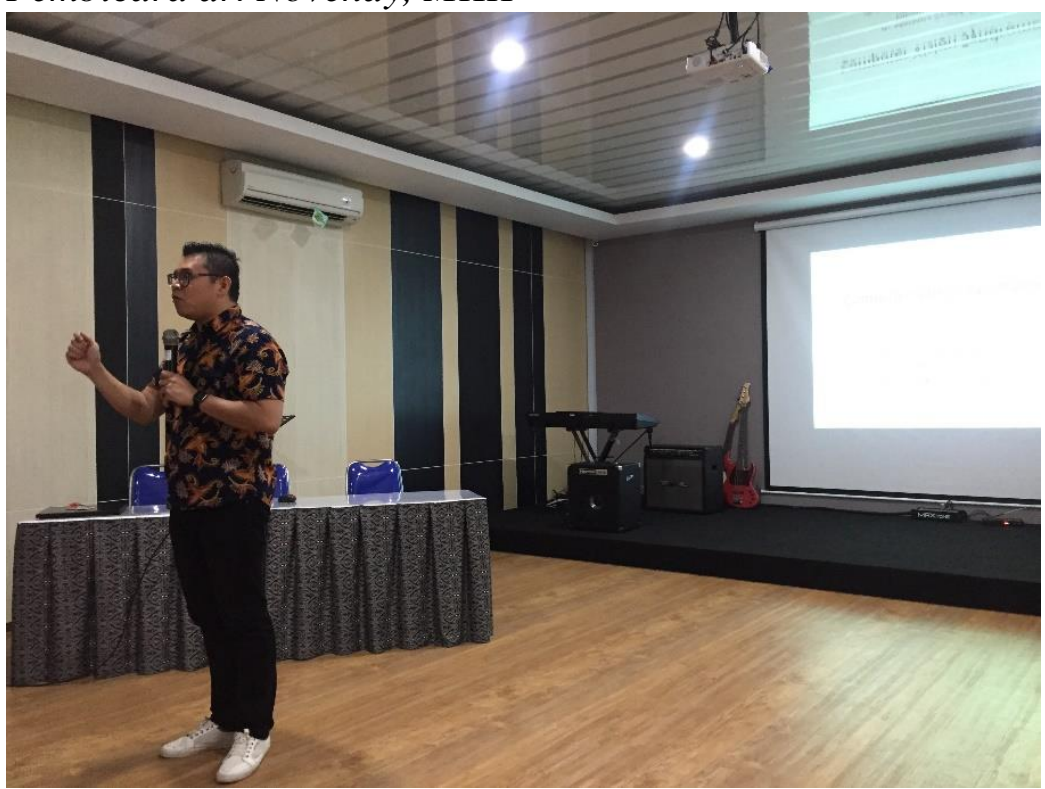




\section{Gambar 3}

\section{Pembicara Meiske Y. Suparman}

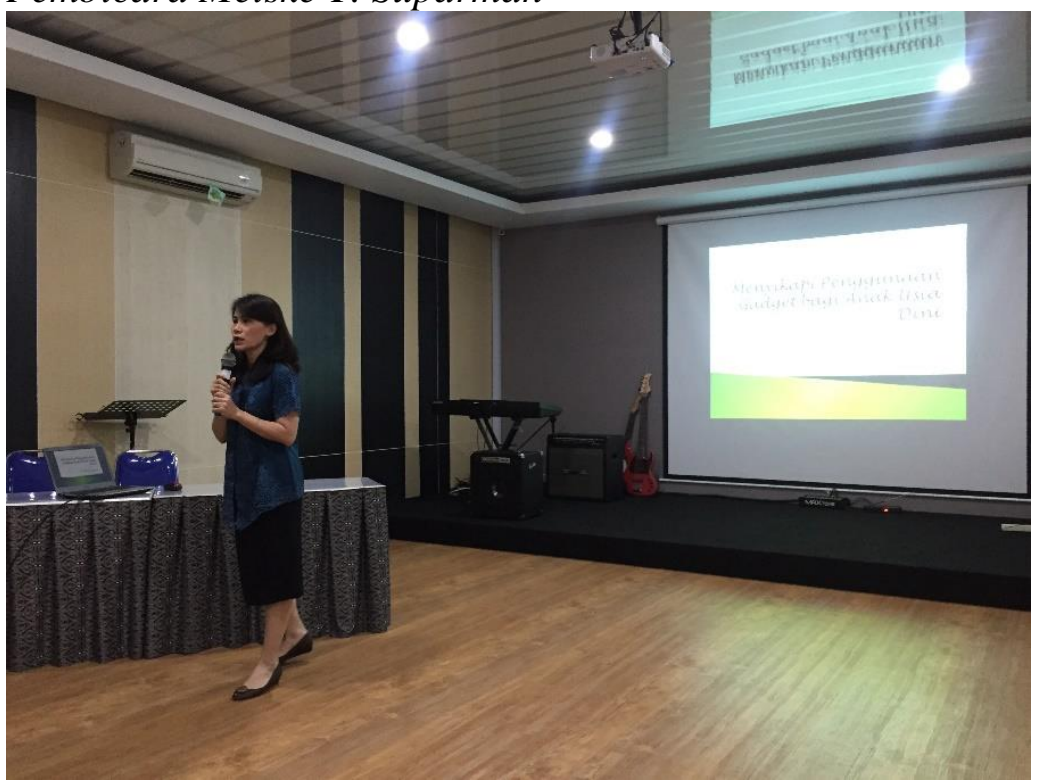

\section{Gambar 4}

Kepala Sekolah dan Guru-guru TKK Sekolah Tunas Harapan Bogor Bersama Tim PKM Universitas Tarumanagara

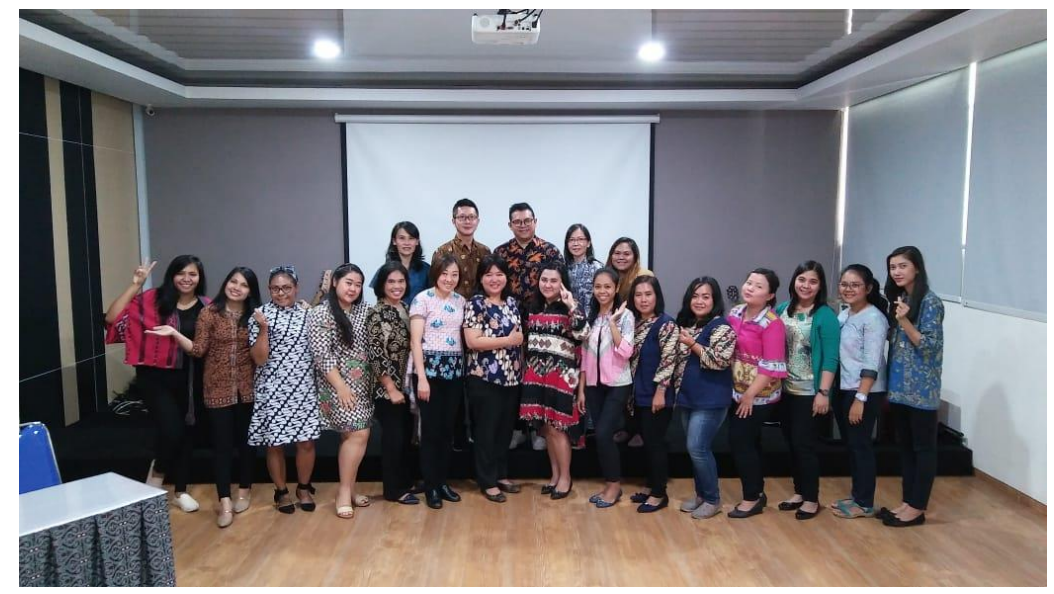

\section{Gambar 5}

\section{Peserta Penyuluhan}

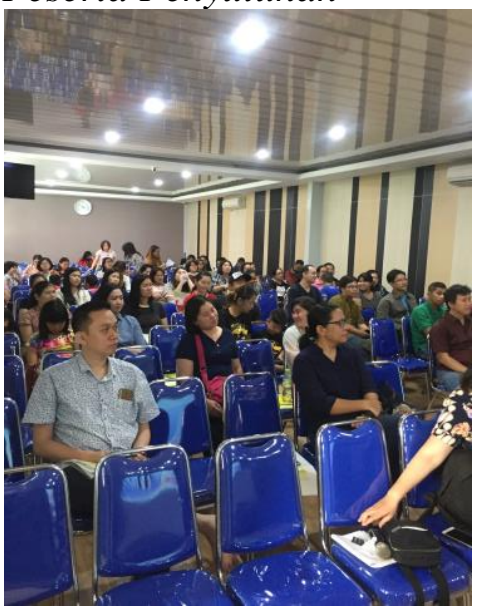




\section{Gambar 5}

Peserta Penyuluhan Peserta pada Saat Registrasi

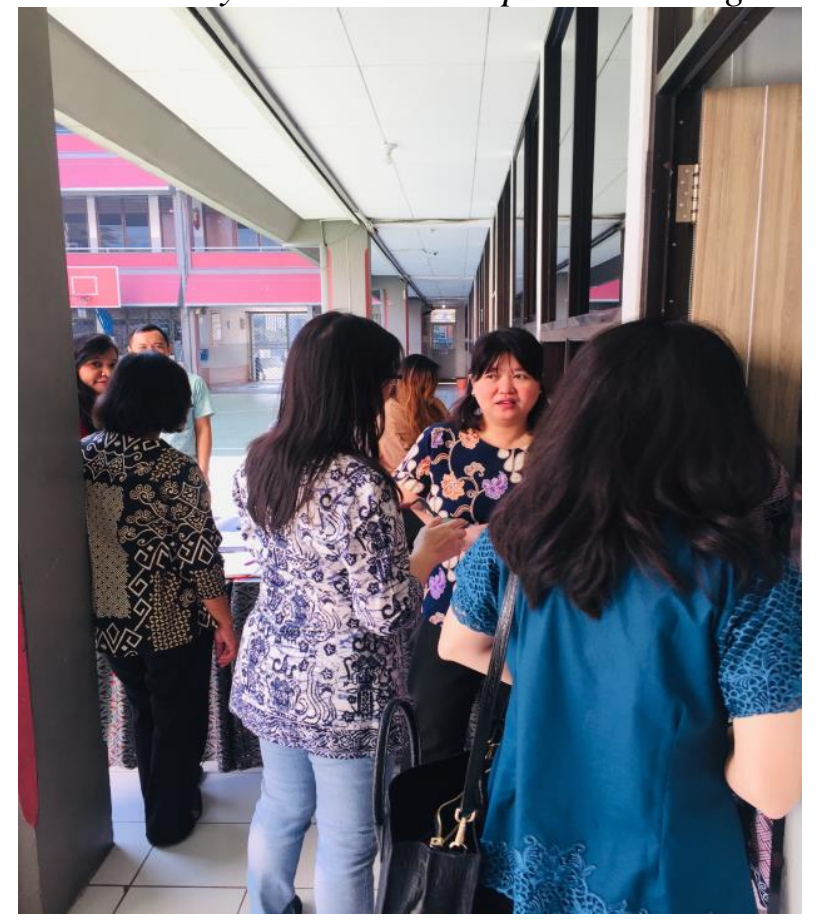

\section{Tabel 1}

Hasil pre-test dan post-test

\begin{tabular}{|c|c|c|c|}
\hline Variabel & $\begin{array}{c}\text { Proporsi }(\%) \\
\quad \mathbf{N}=\mathbf{3 0} \\
\end{array}$ & Mean ; SD & $\begin{array}{c}\text { Median } \\
(\text { min }- \text { maks }) \\
\end{array}$ \\
\hline Hasil pretest & & 49,$44 ; 21,66$ & $50(16,67-83,33)$ \\
\hline Dibawah nilai median & $18(60,0)$ & & \\
\hline Diatas nilai median & $12(40,0)$ & & \\
\hline Hasil posttest & & 68,$88 ; 19,93$ & $66,67(16,67-100)$ \\
\hline Dibawah nilai median & $8(26,7)$ & & \\
\hline Diatas nilai median & $22(73,3)$ & & \\
\hline \multicolumn{4}{|l|}{ Hasil prettest - posttest } \\
\hline Tidak meningkat & $15(50)$ & & \\
\hline Meningkat & $15(50)$ & & \\
\hline
\end{tabular}

\section{KESIMPULAN DAN SARAN}

Pelaksanaan kegiatan PKM "Meningkatkan Pengetahuan Orangtua Mengenai Dampak Penggunaan Gadget pada Anak Usia Dini Terhadap Kesehatan Terutama Mata Anak di TKK Tunas Harapan Bogor" terlaksana dan berjalan dengan baik. Program yang melibatkan kerjasama antara Universitas Tarumanagara dengan Sekolah TKK Tunas Harapan, mendapat apresiasi dan sambutan yang baik dari pihak sekolah dan peserta penyuluhan. Pada kegiatan ini sebanyak 15 peserta $(50 \%)$ peserta mengalami peningkatan pengetahuan setelah dilakukan penyuluhan.

Saran untuk kegiatan ini agar Universitas Tarumanagara dengan Sekolah TKK Tunas Harapan Bogor dapat terus menjalin kerjasama untuk kegiatan dan pengembangan program-program kesehatan terkait masalah pada anak-anak yang perlu dipahami oleh orangtua dan guru. Kegiatan berikutnya diharapkan dapat berupa penyuluhan, pengukuran kegiatan aktifitas anak terkait penggunaan gadget, pemeriksaan mata anak dan pencegahan bahaya dampak gadget dan cara orangtua menangani pembatasan penggunaan gadget pada balita. 


\section{Ucapan Terima Kasih (Acknowledgement)}

Tim PKM mengucapkan terima kasih kepada semua pihak yang telah membantu pelaksanaan kegiatan PKM "Meningkatkan Pengetahuan Orangtua Mengenai Dampak Penggunaan Gadget pada Anak Usia Dini Terhadap Kesehatan Terutama Mata Anak di TKK Tunas Harapan Bogor": Yayasan Tarumanagara, Rektor, Ketua LPPM Universitas Tarumanagara, Dekan, Dosen, Karyawan dan Mahasiswa Fakultas Kedokteran Universitas Tarumanagara, Kepala Sekolah dan Guru-guru TKK Tunas Harapan Bogor, Orangtua siswa TKK Tunas Harapan Bogor.

\section{REFERENSI}

American Optometric Association. (2019). New WHO guidance: Very limited daily screen time recommended for children under 5. https://www.aoa.org/news/clinical-eye-care/publichealth/screen-time-for-children-under-5?sso=y

Aprilia, I. (2018). Dampak buruk terlalu lama lihat gadget pada mata anak. https://www.orami.co.id/magazine/dampak-buruk-terlalu-lama-lihat-gadget-pada-mataanak/

Datareportal. (2018). Digital 2018: Indonesia. https://datareportal.com/reports/digital-2018indonesia (Accessed 31 ${ }^{\text {st }}$ June 2019)

Indonesia Digital Landscape. (2018). Device usage 2018. https://www.slideshare.net/rumahide/indonesia-digital-landscape-

Kozeis, N. (2009). Impact of computer use on children's vision. Hippokratia 13(4), 230-231. PMCID: PMC2776336.

Pusat Data dan Teknologi Informasi Kementerian Pendidikan \& Kebudayaan (n.d.). Data referensi kementerian pendidikan \& kebudayaan. Retrieved from https://referensi.data.kemdikbud.go.id/tabs.php?npsn=20269760 (Accessed $31^{\text {st }}$ June 2019)

Rosiyanti, H. \& Muthmainnah, RN. (2018). Penggunaan gadget sebagai sumber belajar mempengaruhi hasil belajar pada mata kuliah matematika dasar. Fibonacci: Jurnal Pendidikan Matematika dan Matematika, 4(1), 25-36.

Ruder, D., B. (2019). Screen time and the brain: Digital devices can interfere with everything from sleep to creativity. https://hms.harvard.edu/news/screen-time-brain

Sekolah Kristen Tunas Harapan. (2014). Sekolah Kristen Tunas Harapan. http://tunasharapan.sch.id/

Statista Research Departement. (2015). Forecasted number of mobile phone users in Indonesia from 2013 to 2019. https://www.statista.com/statistics/274659/forecast-of-mobile-phoneusers-in-indonesia/

Straker LM, Coleman J, Skoss R, Maslen BA, Burgess-Limerick R, Pollock CM. (2008). A comparison of posture and muscle activity during tablet computer, desktop computer and paper use by young children. Ergonomics, 51(4), 540-555. doi: 10.1080/00140130701711000. PMID: 18357540.

Tim Dapodik. (n.d.). Sekolah kita. https://sekolah.data.kemdikbud.go.id/ index.php/chome/profil/412CF0CF-3A1F-421F-96F2-12AA00F10C18

Winther, DK. (2017). How does the time children spend using digital technology impact their mental well-being, social relationship and physocal activity? An evidence-focused literature review. Innocenti Discussion Paper 2017-02. UNICEF Office of Research - Innocenti Florence. https://www.unicef-irc.org/publications/925-how-does-the-time-children-spendusing-digital-technology-impact-their-mental-well.html 